\title{
Lessons learnt to keep Europe polio-free: a review of outbreaks in the European Union, European Economic Area, and candidate countries, 1973 to 2013
}

T Derrough $^{12}$, A Salekeen ${ }^{12}$

1. European Centre of Disease Prevention and Control (ECDC), Stockholm, Sweden

2. These authors contributed equally to the manuscript

Correspondence: Tarik Derrough (tarik.derrough@ecdc.europa.eu)

Citation style for this article:

Derrough T, Salekeen A. Lessons learnt to keep Europe polio-free: a review of outbreaks in the European Union, European Economic Area, and candidate countries, 1973 to 2013. Euro Surveill. 2016;21(16):pii=30210. DOI: http://dx.doi.org/10.2807/1560-7917.ES.2016.21.16.30210

Article submitted on 27 July 2015 / accepted on 21 April 2016 / published on 21 April 2016

Between 1973 and 2013, 12 outbreaks of paralytic poliomyelitis with a cumulative total of 660 cases were reported in the European Union, European Economic Area and candidate countries. Outbreaks lasted seven to 90 weeks (median: 24 weeks) and were identified through the diagnosis of cases of acute flaccid paralysis, for which infection with wild poliovirus was subsequently identified. In two countries, environmental surveillance was in place before the outbreaks, but did not detect any wild strain before the occurrence of clinical cases. This surveillance nonetheless provided useful information to monitor the outbreaks and their geographical spread. Outbreaks were predominantly caused by poliovirus type 1 and typically involved unvaccinated or inadequately vaccinated groups within highly immunised communities. Oral polio vaccine was primarily used to respond to the outbreaks with catchup campaigns implemented either nationwide or in restricted geographical areas or age groups. The introduction of supplementary immunisation contained the outbreaks. In 2002, the European region of the World Health Organization was declared polio-free and it has maintained this status since. However, as long as there are non-vaccinated or under-vaccinated groups in European countries and poliomyelitis is not eradicated, countries remain continuously at risk of reintroduction and establishment of the virus. Continued efforts to reach these groups are needed in order to ensure a uniform and high vaccination coverage.

\section{Introduction}

In 1995, the Global Commission for the Certification of the Eradication of Poliomyelitis (GCC) was established to oversee polio eradication certification activities on a global level. The commission defined essential monitoring systems on which the certification of eradication should be based - the surveillance for acute flaccid paralysis (AFP) and for wild poliovirus. These technical requirements reflected the basic principles of the
World Health Organisation (WHO) for the eradication of wild poliovirus (WPV), which were to (i) achieve and maintain high routine immunisation coverage; (ii) improve surveillance systems (including AFP surveillance) and (iii) conduct supplementary immunisation activities (SIAs), including national immunisation days (NIDs) in all endemic areas and mopping-up immunisation in high risk areas in low incidence countries [1]. Substantial progress has been made to reach worldwide eradication. However, specific areas continue to cause concern. At the beginning of 2015, Afghanistan and Pakistan continued to have circulation of WPV type 1 (WPV1) [2].

In 1998, the last case of poliomyelitis caused by endemic WPV in the WHO European Region occurred in eastern Turkey, in an unvaccinated two-year-old. In 2001, this Region experienced its last outbreak of WPV with cases in Bulgaria. In 2002, the European Region of WHO was declared polio free and has since maintained this status [3]. However, this is repeatedly challenged. In 2010, WPV1 imported from Pakistan caused a large outbreak in Tajikistan that spilled over into neighbouring countries [4]. From February 2013 to March 2014, Israel detected WPV1 in sewage samples [5]. However, no clinical cases of polio were notified in Israel, the West Bank or the Gaza Strip. Since late 2013, some incidents related to polio have also been reported from countries boarding the WHO European Region. In October of that year, Syria confirmed WPV circulation [5]. In March 2014, Iraq reported its first case of paralytic poliomyelitis since 2000 [6]. In September 2014, a factory in Belgium accidentally released WPV into a river that flows through areas populated with communities with suboptimal coverage against poliomyelitis in the Netherlands [7]. These events reminded countries in Europe that poliovirus could be reintroduced as long as it has not been eradicated. Given the presumed population flow to and from countries where WPV is 
still circulating and the social and geographical clustering of population groups with low vaccine uptake in Europe [8], WPV could be imported and re-established.

In the 1960 s, mass vaccination against poliomyelitis started in the European Union (EU)/European Economic Area (EEA) [9], increasing coverage in the general population. Until 1973 there were significant variations in vaccination coverage, leaving large immunity gaps in the population and outbreaks of poliomyelitis continued to occur [9]. After 1973, when coverage was higher, outbreaks were less common. A better understanding of these post 1973 outbreaks could support our assessment of the current risk for WPV reintroduction in Europe and inform preparedness for responding to any such reintroduction. We systematically reviewed published reports of outbreaks of poliomyelitis affecting the EU/EEA and its candidate countries during the period from January 1973 to December 2013 to characterise populations affected, describe response measures and understand the role of environmental surveillance.

\section{Methods}

\section{Search strategy}

We conducted a systematic literature search to identify original articles in PubMed and Embase bibliographic databases as of 5 March 2014. The search strategies submitted were combining controlled vocabulary (MeSH and Emtree terms) and natural vocabulary for representing the concepts of 'poliomyelitis', 'outbreak', and 'case/case report'. We defined the period of interest as a forty year period from 1973 to 2013 . Geographical terms were included in the search strings in order to retrieve more accurate results. The geographical terms included all EEA countries and EU Member States (MS), as well as candidate and potential candidate countries for the EU (as of 24 November 2014, these countries were: Albania, Bosnia and Herzegovina, Iceland, Kosovo under UN Security Council Resolution 1244, Montenegro, Serbia, the former Yugoslav Republic of Macedonia, and Turkey) [10]. The search was not restricted by date or language. Outbreaks outside the area of interest were included in the review but informed the discussion.

\section{Data abstraction}

We initially screened articles retrieved through the search based on the title and abstract to identify papers that fulfilled at least two of the following inclusion criteria:

(i) The paper reported or described a single case or clustering of cases of WPV in a country or area;

(ii) The paper provided concrete data on one or more EU/EEA countries and candidate countries or areas affected within; (iii) The paper reported on response measures to an outbreak.

Reports were included in the full text analysis if they were in Dutch, English, French, Italian, Polish or Spanish. Reports were excluded if they only referred to areas outside of the EU/EEA and candidate countries, or if they described long-term trends in poliomyelitis epidemiology. Missing abstracts or abstracts that did not provide sufficient information to be definitely excluded from the study were also included in the full text analysis.

We abstracted data from articles according to a predefined template to recover information on (i) date of onset of cases, detection, response and the date of the final case; (ii) type of vaccine used in the SIAs; (iii) use of environmental surveillance to detect or manage the outbreak and (iv) socio-demographic characteristics of the affected population.

\section{Data analysis}

An outbreak was defined as a single case or a clustering of cases of WPV in a country or area in excess of what normally would be expected, where routine vaccination was already in place and for which response measures had to be implemented. We analysed the data abstracted to estimate the number of cases and the case fatality ratio and to describe geographical spread, type of poliovirus involved, and characteristics of the population affected (e.g. age groups, general population vs specific subgroup). We categorised outbreaks as to whether they were associated with poor access to vaccination, poor availability of the vaccine or lack of acceptance of the vaccination. We calculated the duration of the outbreak as well as the time taken to respond. If there were no exact dates reported, we used information available to estimate the duration of the outbreak.

\section{Results}

\section{Results of the search}

The literature search retrieved 738 records and articles after deduplication, of which 97 fulfilled the inclusion criteria. The full text evaluation identified 45 of these articles as relevant for this study from which data would be abstracted and a further three which could offer complementary data on already retrieved outbreaks (Figure).

\section{Outbreaks identified}

Twelve outbreaks were reported across eight countries of interest in the period from 1975 to 2001 (Table). Six of 12 outbreaks included more than three areas, where clinical cases were reported in a country and were thus classified as national outbreaks. On four occasions epidemiological and microbiological investigations identified cases and established chains of transmission in other countries, from the Netherlands to Canada in 1978 and 1992 [11,12], from Albania to Greece and 


\section{FIGURE 1}

Flow diagram for the selection of studies on polio in the European Union /European Economic Area and candidate countries $^{\mathrm{a}}$, published 1973-2013 $(\mathrm{n}=738)$

IDENTIFICATION

TITLE/ABSTRACT SCREENING

FULL PAPER/REPORT SCREENING

\section{RECORDS RETRIEVED}

975 records retrieved prior to deduplication

Medline (Pubmed): 385

Embase (embase.com): 590

738 records after deduplication

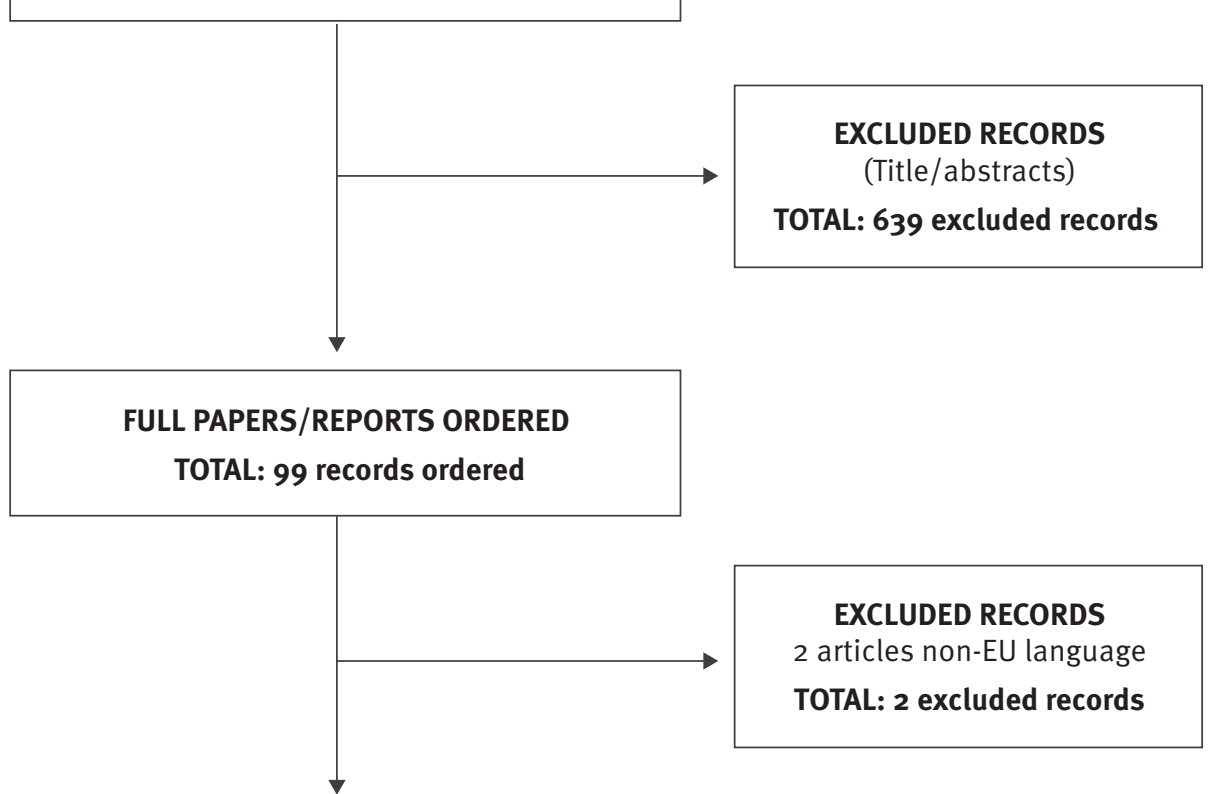

FULL PAPERS/REPORTS ASSESSED

TOTAL: 97 records assessed

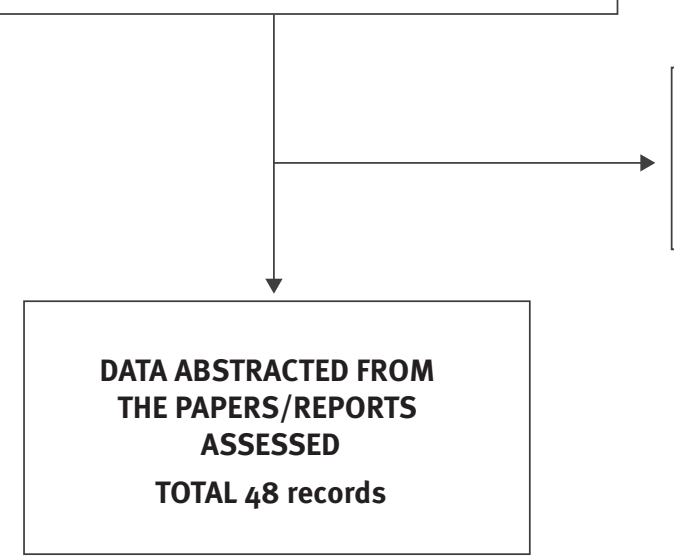

DATA NOT ABSTRACTED

(Full papers/reports)

TOTAL: 49 records

\footnotetext{
a As of 24 November 2014, these countries were: Albania, Bosnia and Herzegovina, Iceland, Kosovo under UN Security Council Resolution 1244, Montenegro, Serbia, the former Yugoslav Republic of Macedonia, and Turkey.
} 
Kosovo under UN Security Council Resolution 1244 in 1996 [13], and from Bulgaria to eight countries in 1991 [14].

The number of clinical cases reported within the outbreaks ranged from one to 161 , with the largest outbreaks in Romania in 1980 (161 cases), Albania in 1996 (143 cases) and the Netherlands in 1978 (110 cases).

\section{Age distribution}

In five outbreaks (1977 in Sweden, 1978 in Albania, 1980-1982 and 1990-1992 in Romania and 2001 in Bulgaria) the age of the affected population ranged from six months to three years with a median age of less than two years (Table). An additional outbreak in Bulgaria from 1990 to 1991 mainly concerned the same age group, whereby the median age was reported to be less than a year, and except for one adult case, all cases were less than 18 months-old. In two outbreaks (1975 in Germany and 1978 in the Netherlands), the median ages were respectively of 6.5 and 10.5 years with a range of $<1-20$ years. In three outbreaks (1984-1985 in Finland, 1992-1993 in the Netherlands and 1996 in Albania) the median age was between 18 and 28 years-old with the total age range from $<1$ to 61 years. Only in one outbreak (1976 in Greece) was the age of the affected population not specified.

\section{Case fatality}

Whether deaths occurred or not within an outbreak was reported in seven of the 12 outbreaks. Among these seven, two outbreaks had no fatalities. For the outbreaks where deaths were reported, there were in total 21 deaths for 351 cases corresponding to an overall case fatality ratio of $6 \%$. Of the 21 deaths reported, 16 occurred during the 1996 outbreak in Albania that had the highest case fatality ratio (16/145: 11\%) [15]. The distribution of deaths across age groups was as follows: three deaths in those under 10 years of age with one death among an infant under one year-old; six deaths among 11 to 18 year-olds, seven deaths among 19 to 25 year-olds and five deaths (23\%) in cases older than 26 years.

\section{Social characteristics of the affected population} and vaccine efficacy

Five of the 12 outbreaks occurred in vulnerable groups for which access to healthcare, including vaccination presented difficulties. Of these five outbreaks, four were specifically among the Roma population (Greece in 1976, Romania from 1990-1992, and in Bulgaria in 1990-1991 and in 2001) and one among families from low income groups (Germany in 1975). Three of the 12 outbreaks affected specific geographically clustered communities refusing vaccination on religious grounds while no clinical cases were reported in the general population (two in the Netherlands in 1978 and 1992-1993 and one in Sweden in 1977) [16-20]. Three of the 12 outbreaks occurred among the general population (Romania 1980-1982, Finland 1984-1985 and Albania 1996). Only one outbreak in Albania (1978) did not specify the social characteristics of the affected population.

Four of the 12 outbreaks occurred due to problems within programmes, or problems with the regular vaccine, its supply and/or distribution. Programmatic errors lead to disruptions in the regular polio vaccination programmes or resulted in the use of a vaccine with suboptimal efficacy. Prior to the 1978 outbreak in Albania, there was an interruption in supply of vaccine imported from China, which led to decreased coverage. In 1984 in Finland, the polio vaccine used in routine vaccination programmes was of lower potency against one of the polio strains (polio type 3) which, in combination with decreasing vaccination coverage among the general population, may have contributed to the occurrence of clinical cases [21]. In 1980 in Romania, a monovalent type 1 oral polio vaccine (OPV), given as a single dose at six weeks of age, resulted in cases among cohorts that were inadequately vaccinated [22]. In 1996 in Albania, a concurrence of different circumstances and events contributed to reduced vaccination coverage. First, OPV was stored for several years at room temperature, which affected its potency. Second, population movement from endemic countries and the unstable regional political environment lead to WPV importation. WPV then circulated among unprotected segments of the population $[15,23,24]$.

\section{Identification of outbreaks}

The duration of the outbreaks varied between seven to 90 weeks for nine outbreaks where data was available. In all outbreaks, identification of the outbreak was due to diagnosis of cases of AFP, following which poliovirus was identified through a laboratory investigation. In 1991 in Bulgaria, the onset of paralysis in the first suspected case was in late December 1990 and the polio diagnosis was in late January 1991 [14]. In the Netherlands in 1978, polio was suspected four weeks after paralysis [17]. These patients had presented with AFP to a medical facility but the diagnosis was initially not suspected and diagnosis was delayed [17].

\section{Timeliness of response}

The exact start date of the SIA was only available in four (Finland in 1984; Bulgaria in 1991; the Netherlands 1992 and Albania in 1996) of the outbreaks. In three outbreaks the number of weeks had to be estimated because only a month but not a day was specified. For those where exact dates were specified, the response time ranged between one and 24 weeks. The quickest response was in the Netherlands in 1992 (first case: 17 September, beginning of the SIAs: 22 September, five days later).

\section{Vaccine used in supplementary immunisation activities}

In seven of the 12 outbreaks, OPV was used exclusively in SIAs. In five of these, tOPV was used and in two outbreaks the exact type of OPV was unspecified. In two outbreaks, OPV was used in combination 


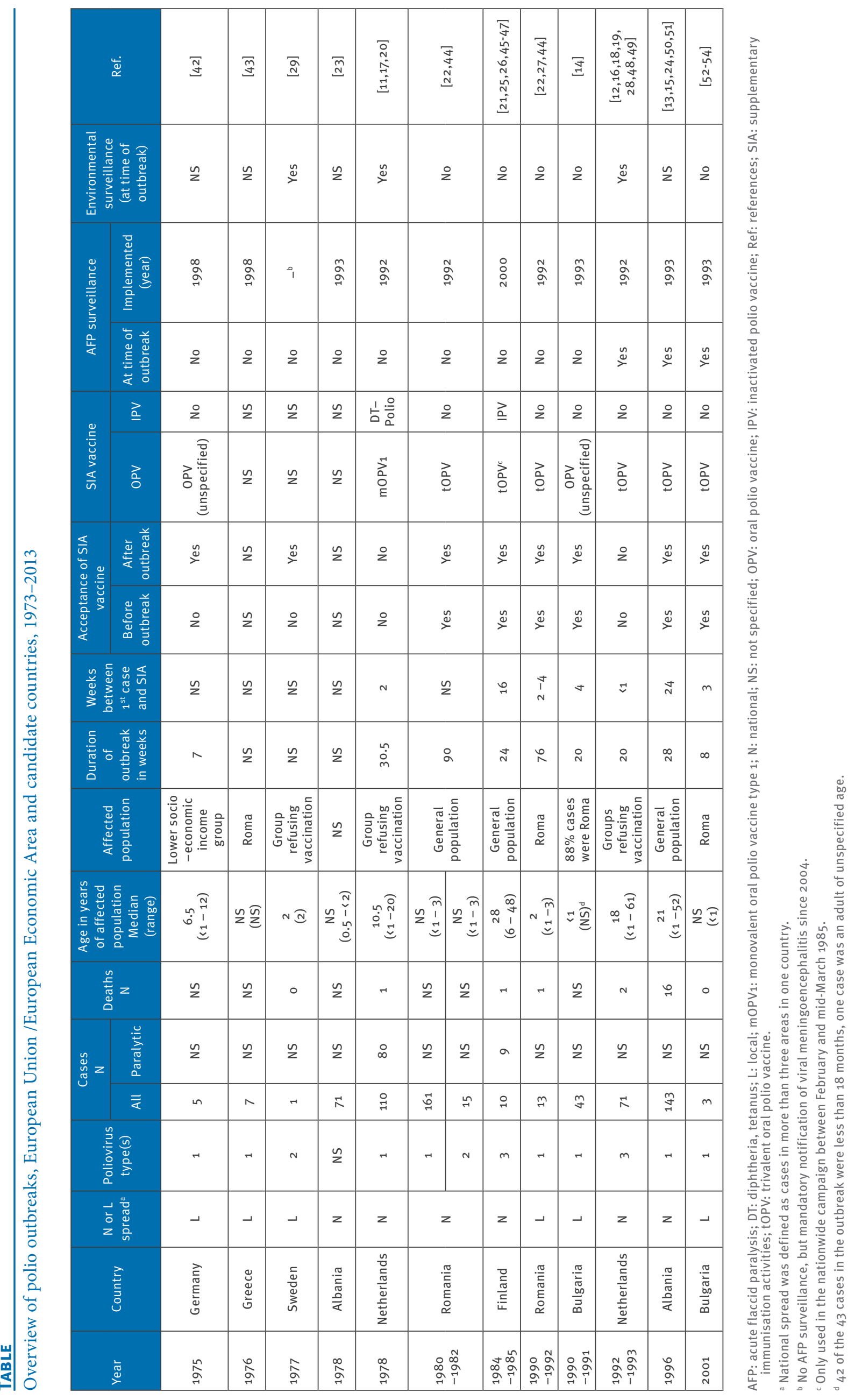


with inactivated polio vaccine (IPV). In 1978 in the Netherlands, diphtheria tetanus (DT)-polio was used in combination with mOPV 1 [17]. In 1984 to 1985 in Finland, IPV was used in addition to tOPV, although the tOPV was only used in the nationwide campaign [25]. In three outbreaks the vaccine used for response was not specified.

\section{Supplementary immunisation activities' strategies}

Catch-up campaigns were implemented either nationwide or restricted in terms of geographical areas or age groups. In 1978 and 1992 in the Netherlands, catch-up vaccinations with OPV were offered to those with direct contact with cases or to those who had been incompletely vaccinated through the regular vaccination programme with IPV. In 1984, Finland initially intensified the national vaccination programme of preschool aged children with IPV from November 1984 (first case diagnosed in October 1984) and in total 1.5 million doses of IPV were administered. Vaccination was then extended for all adults when cases were reported in this age group [21,26]. In 1990 in Romania, SIAs were conducted in four districts where cases had been reported. Immunisation occurred on a house-to-house basis with 102,000 children vaccinated with OPV (96\%<3 years) [27]. In 1991 in Bulgaria, mass vaccination was conducted for all Roma children $<7$ years of age. In addition, all other children among the general population $<1.5$ years of age were vaccinated [14]. In 2001 in Bulgaria, SIAs were conducted for children $<8$ years of age in the area affected by the outbreak as well as three neighbouring districts.

\section{Environmental surveillance}

In Sweden (1977) and the Netherlands (1978), environmental surveillance was in place and routinely used before the outbreaks of poliomyelitis. However, in both outbreaks WPV was not detected in sewage or recreational water before the onset of the first clinical case [28,29]. In 1977 in Sweden, after the outbreak had been detected, WPV type 2 was isolated from sewage systems that served the affected area as well as other parts where no people known to shed the virus lived. The virus was also isolated from sewage plants in Stockholm. Faecal specimens from close contacts, other contacts and individuals with no known contact to cases suggested circulation only in close contacts (25 schoolchildren and families from the same group refusing vaccination, all unvaccinated) [29]. In 1978 in the Netherlands, environmental surveillance indicated that circulation of the virus did not affect the population immunised with IPV or unvaccinated people living within well-vaccinated communities [20]. Wild poliovirus circulated only within sections of the populations that had, on the whole, refused vaccination.

In 1982, Finland had discontinued its nationwide systematic environmental surveillance but with the diagnosis of first case in August 1984 collection and testing of environmental was resumed. Sewage specimens yielded results positive for WPV until February 1985 and indicated a geographical spread of the outbreak strain in the vaccinated population. Vaccine-type virus was subsequently isolated in sewage specimens 14 weeks after the vaccination campaign and 100,000 people were estimated to be shedding WPV 3 . The last specimen with documented poliovirus content was collected in Helsinki late June 1985, more than eight weeks after the OPV vaccination campaign [25].

In 1992 in the Netherlands, environmental surveillance did not detect circulation of the virus before the first case but it did retrospectively confirm that WPV type 3 had circulated three weeks before the first clinical cases ten kilometres from where this case was reported [28]. It confirmed the precise location of the infection and suggested the possibility that people living in villages downstream from the initial case might be exposed. In doing so, it allowed for the targeted intervention of SIAs. Environmental investigations identified WPV in 23 of 269 samples from sewage pipelines in 120 locations, only in the risk area.

\section{Discussion}

In our review, those most affected by poliomyelitis outbreaks were communities within the general population who were not vaccinated or under vaccinated. These can be split into two groups. The first group comprises populations that are hard to reach (e.g. the Roma community) or people living in poor socio-economic environments. They are not inherently opposed to vaccination but they may have poor access to vaccination or lack awareness of the importance of vaccination against polio. The second group includes those who refused vaccination, such as the anthroposophic and religious communities. This included communities in the Netherlands, where vaccine acceptance is influenced by factors such as how convenient it is to get vaccinated, complacency regarding not being vaccinated and confidence in the vaccine [30]. People who refuse vaccination may also do so either because they are hesitant about whether or not to get vaccinated, or alternatively because they are opposed to vaccination.

In 2015, the WHO's Strategic Advisory Group of Experts on Immunization (SAGE) examined the causes of vaccine hesitancy in order to identify approaches to increase global vaccination acceptance [31]. Vaccine hesitancy is addressed in guidelines from public health organisations in Europe, which aim to provide methods and tools to assist national immunisation programmes to design targeted strategies that increase vaccination uptake [32,33].

Groups opposing vaccination are not unique to Europe. In Nigeria, India and Pakistan, groups refusing vaccination against polio and limiting vaccination efforts almost brought the elimination of polio to a standstill [34]. India and Nigeria have engaged with the groups opposing vaccination and the results have shown that such interventions have a positive impact on vaccination 
uptake. To increase vaccination uptake among groups refusing vaccination the $\mathrm{WHO}$, regional and local policymakers and non-governmental organisations (NGOs) set up programmes specifically targeting these groups. These outreach programmes focused on interpersonal communication and social mobilisation as a route to changing social norms around vaccination by engaging local opinion leaders and organisations with influence in their communities [35].

The outbreaks affecting initially unvaccinated communities reviewed in this study did not spread to the general population or to subgroups of the general population with suboptimal vaccination coverage that lived within well-vaccinated communities. Outbreaks within the general population occurred only when there was a disruption in the normal vaccine distribution and storage. The age groups affected were best explained by poliomyelitis susceptibility gaps, highlighting the role of routine childhood immunisation and catch-up programmes to protect the whole population.

In all outbreaks, cases were detected when presenting with AFP and confirmed with laboratory tests. Not all countries had implemented AFP surveillance at the time of the outbreaks (Table). In our review, prompt introduction of SIA and catch-up vaccinations contributed to a marked decline of cases. Rapid response in the affected community is crucial to bringing an outbreak under control. Evidence on early containment also stemmed from the experience of outbreaks that were not included in our literature review. In April 2010, Tajikistan faced a large outbreak of poliomyelitis that spread to four neighbouring countries (Kazakhstan, Russia, Turkmenistan and Uzbekistan) [36]. The rapid, large scale SIA response targeting affected areas and age groups quickly brought the outbreak under control. In July to October 2011, China experienced a polio outbreak in southern Xinjiang. Four weeks after confirmation of the outbreak, China launched SIAs and the outbreak was stopped within six weeks of the laboratory confirmation of the index case. Aggressive action, including widespread vaccination of susceptible hosts, interrupted the outbreak quickly [37]. The WHO has issued poliomyelitis outbreak response guidelines, which suggests that after laboratory confirmation, SIAs need to start as soon as possible [38].

The European Regional Certification Commission for Poliomyelitis RCC and the WHO have included environmental surveillance in their eradication strategic plans to supplement AFP surveillance [39]. Regular environmental surveillance is already in place in Croatia, Estonia, Finland, Italy, Latvia and Lithuania and as of March 2015, the European Office of the WHO was in the final stage of the production of guidelines on environmental surveillance for detection of poliovirus [39]. In 2013 in Israel, environmental surveillance served as an early warning tool and allowed the public health authorities to take immediate preventive measures [5]. In the two countries in this review where environmental surveillance was in place, the surveillance did not detect WPV circulation before the detection of clinical cases. However, as the outbreaks in Sweden, the Netherlands and Finland suggested, environmental surveillance provided an understanding as to when transmission started, delineated the geographical spread of transmission, including possible locations where there might have been a risk of exposure, and allowed for targeted SIAs.

This review has some limitations. First, we lacked the information to identify which vaccine was most suitable to respond to an outbreak. The response at the time depended on the availability of the vaccine. Further analysis on the impact of SIAs would be useful in evaluating the effectiveness of response measures, in order to improve these measures as well as the timeliness of the response, for which information was only available in four of the outbreaks. Second, the review did not address outbreaks caused by vaccine derived polio viruses (VDPV). This was outside the scope of the review although we acknowledge that in the postelimination phase VDPV may circulate in settings with low coverage and OPV use. On 28 August 2015, two cases of paralytic poliomyelitis caused by circulating vaccine-derived poliovirus type 1 (cVDPV1) were confirmed in Ukraine. According to an initial assessment, the risk of importation to the EU is considered as low but it served as another reminder to countries that polio remains a threat and to conduct a rapid review of national polio outbreak response plans [2]. Third, the review did not allow for the identification of the environmental surveillance schemes that would best detect WPV before clinical cases, including which geographical areas need to be sampled to monitor areas close to at risk-populations. As such, our findings do not provide a robust evidence base for decisions relating to the use of, and the sampling strategy for, environmental surveillance, particularly in the absence of an outbreak.

Our review leads us to a number of conclusions. First, the key element for Europe to remain polio free is to ensure uniform, high vaccination coverage. As long as there are non-vaccinated or under-vaccinated groups in European countries and poliomyelitis is not eradicated, these groups are continuously at risk. Second, there is an ongoing need to address the problem of groups who refuse vaccination and have low confidence in vaccination programmes. They represent a potential reservoir for WPV and the setting for clinical cases. Third, when outbreaks occur, quick intervention through SIAs is important to allow rapid containment. Fourth, while environmental surveillance may not detect wild strains before the occurrence of clinical cases, it may provide useful information for monitoring and controlling outbreaks, such as their geographical extent.

To protect Europe from reintroduction of polio, we first need to identify ways to increase the vaccination coverage in the pockets of under-immunised populations. 
To do so, it is important to ensure that all communities have facilitated access to vaccination and are informed of its benefits. Confidence in vaccination programmes must be improved in groups that refuse vaccination, maybe through targeted interpersonal outreach and communication through mediators from these communities. A trustworthy dialogue should be started with the parental groups refusing vaccination, moreover their meeting and interaction with healthcare professionals should be improved [40]. If reintroduction occurs, SIAs must be conducted with the vaccine readily available so as not to delay the intervention and according to the WHO guidelines for outbreak response [41]. Lastly, lessons learnt from past outbreaks on the failure of environmental surveillance schemes to detect WPV circulation before the identification of clinical cases should be taken into account in developing guidance on conducting environmental surveillance near vulnerable populations. However, the recent example of the detection of silent transmission of WPV 1 through environmental surveillance in Israel has shown the potential of this method to serve as a useful early warning system to mitigate the risk of reintroduction of WPV [5].

\section{Acknowledgements}

We would like in particular to thank Yvan Hutin for his very helpful comments and suggestions for the manuscript. We would like to thank Elizabeth Bancroft, Lucia PastoreCelentano, for their support and their review of earlier drafts of the manuscript. We would like to thank Irene Muñoz Guajardo for support in retrieving the relevant literature.

\section{Conflict of interest}

None declared.

\section{Authors' contributions}

Tarik Derrough and Alexandra Salekeen both contributed equally to this paper and were responsible for data abstraction, summarisation and drafting of the manuscript. All authors revised and approved the final version of the manuscript.

\section{References}

1. World Health Organization (WHO). Report of the 1st Meeting of the Global Commission for the Certification of the Eradication of Poliomyelitis [internet]. Geneva: WHO; 1995/ [Accessed 15 Oct 2015]. Available from: http://www.polioeradication. org/Portals/o/Document/Resources/1st\%20Global\%20 CertCom\%2oMeeting\%2oReport\%201996.PDF

2. Global Polio Eradication Initiative. Polio this week. 2015. [Accessed 15 Oct 2015]. Available from: http://www. polioeradication.org/Dataandmonitoring/Poliothisweek.aspx

3. World Health Organization (WHO). Certification of Poliomyelitis Eradication. Fifteenth meeting of the European Regional Certification Commission. Copenhagen, 19-21 June 2002. Geneva: WHO; 2002. [Accessed 12 Oct 2015]. Available from: http://www.euro.who.int/__data/assets/pdf_file/0003/79374/ E88105.pdf

4. World Health Organization (WHO). Poliomyelitis in Tajikistan: first importation since Europe certified polio-free. Geneva: WHO; 2010. [Accessed 12 Oct 2015]. Available from: http:// www.who.int/wer/2010/wer8518.pdf
5. World Health Organization (WHO). Polio outbreak in the Middle East - update. 21 Mar 2014. [Accessed 9 Dec 2014]. Available from: http://www.who.int/csr/don/2014_3_21polio/en/

6. World Health Organization (WHO). Polio outbreak in the Middle East - update. Ongoing transmission in the Syrian Arab Republic with international spread. Disease outbreak news. 21 MARCH 2014. Geneva: WHO. [Accessed 20 Apr 2016]. Available from: http://www.who.int/csr/don/2014_3_21polio/en/

7. European Centre for Disease Prevention and Control (ECDC). Monitoring current threats: ECDC Communicable Disease Threats Report (CDTR), week 37/2014. Stockholm: ECDC; 2014. [Accessed 12 Oct 2015]. Available from: http://www.ecdc. europa.eu/en/press/news/_layouts/forms/News_DispForm. aspx?List $=8 \mathrm{db} 7286 \mathrm{c}-\mathrm{fe} 2 \mathrm{~d}-476 \mathrm{c}-9133-18 \mathrm{ff} 4 \mathrm{cb} 1 \mathrm{~b} 568 \mathrm{6}$ \&ID $=1065$

8. Muscat M. Who gets measles in Europe?J Infect Dis. 2011;204(Suppl 1):S353-65. DOI: 10.1093/infdis/jiro67 PMID: 21666185

9. Vidor E, Plotkin SA. Poliovirus vaccine-inactivated. In: Plotkin SA, Orenstein WA, Offit PA, editors. Vaccines. 6th ed. Philadelphia: Saunders Elsevier; 2013. p. 573-97.

10. European Commission. European Neighbouring Policy. 24 Nov 2014. [Accessed 12 Oct 2015]. Available from: http://ec.europa. eu/enlargement/countries/check-current-status/index en.htm

11. Furesz J. Poliomyelitis outbreaks in the Netherlands and Canada.Can Med Assoc J. 1979;120(8):905-6.PMID: 436062

12. Drebot MA, Mulders MN, Campbell JJ, Kew OM, Fonseca K, Strong D, et al. Molecular detection of an importation of type 3 wild poliovirus into Canada from The Netherlands in 1993. Appl Environ Microbiol. 1997;63(2):519-23.PMID: 9023931

13. Arya A. Outbreak of poliomyelitis in Albania and neighboring countries in 1996.J Clin Microbiol. 1999;37(1):276.PMID: 9988592

14. Expanded programme on immunization. Poliomyelitis outbreak. Wkly Epidemiol Rec. 1992;67(45):336-7.PMID: 1419570

15. Prevots DR. Ciofi degli Atti ML, Sallabanda A, Diamante E, Aylward RB, Kakariqqi E, et al. Outbreak of paralytic poliomyelitis in Albania, 1996: high attack rate among adults and apparent interruption of transmission following nationwide mass vaccination. Clin Infect Dis. 1998;26(2):419-25.

16. Oostvogel PM, van Wijngaarden JK, van der Avoort HG, Mulders MN, Conyn-van Spaendonck MA, Rümke HC, et al. Poliomyelitis outbreak in an unvaccinated community in The Netherlands, 1992-93. Lancet. 1994;344(8923):665-70. DOI: 10.1016/S0140-6736(94)92091-5 PMID: 7915354

17. Bijkerk H. Poliomyelitis epidemic in the Netherlands, 1978.Dev Biol Stand. 1979;43:195-206.PMID: 230110

18. Oostvogel PM, Rumke HC, Conyn-Van Spaendonck MA, van der Avoort HG, Leeuwenburg J, van Loon AM. Poliovirus circulation among schoolchildren during the early phase of the 19921993 poliomyelitis outbreak in The Netherlands.J Infect Dis. 2001;184(11):1451-5. DOI: 10.1086/324327 PMID: 11709788

19. van Wijngaarden JK, van Loon AM. The polio epidemic in The Netherlands, 1992/1993. Public Health Rev. 1993-19941994;21(1-2):107-16.PMID: 8041875

20. Schaap GJ, Bijkerk H, Coutinho RA, Kapsenberg JG, van Wezel $A L$. The spread of wild poliovirus in the well-vaccinated Netherlands in connection with the 1978 epidemic.Prog Med Virol. 1984;29:124-40.PMID: 6322230

21. Centers for Disease Control and Prevention. Update: poliomyelitis outbreak-Finland, 1984-1985 [internet]. 1986 [cited 2015 Oct. 12]. Available from: http://www.cdc.gov/ mmwr/preview/mmwrhtml/o0000682.htm.

22. Baicus A. History of polio vaccination.World J Virol. 2012;1(4):108-14. DOI: 10.5501/wjv.v1.i4.108 PMID: 24175215

23. Diamanti E, Ibrahimi B, Tafaj F, Mezini E, Dodbiba A, Dobi $V$, et al. Surveillance of suspected poliomyelitis in Albania, 1980-1995: suggestion of increased risk of vaccine associated poliomyelitis. Vaccine. 1998;16(9-10):940-8. DOI: 10.1016 So264-410X(98)80025-X PMID: 9682341

24. Centers for Disease Control and Prevention (CDC). Poliomyelitis outbreak-Albania, 1996. Atlanta: CDC; 1996. [Accessed 12 Oct 2015]. Available from: http://www.cdc.gov/mmwr/preview/ mmwrhtml/ooo43798.htm

25. Pöyry T, Stenvik M, Hovi T. Viruses in sewage waters during and after a poliomyelitis outbreak and subsequent nationwide oral poliovirus vaccination campaign in Finland.Appl Environ Microbiol. 1988;54(2):371-4.PMID: 2833160

26. Hovi T, Cantell K, Huovilainen A, Kinnunen E, Kuronen T, Lapinleimu K, et al. Outbreak of paralytic poliomyelitis in Finland: widespread circulation of antigenically altered poliovirus type 3 in a vaccinated population. Lancet. 1986;1(8495):1427-32. DOI: 10.1016/S0140-6736(86)91566-7 PMID: 2872526 
27. Roure C, Oblapenko G. Communicable diseases in the CCEE/ NIS.World Health Stat Q. 1993;46(3):177-87.PMID: 8017075

28. van der Avoort HG, Reimerink JH, Ras A, Mulders MN, van Loon AM. Isolation of epidemic poliovirus from sewage during the 1992-3 type 3 outbreak in The Netherlands.Epidemiol Infect. 1995;114(3):481-91. DOI: 10.1017/S0950268800052195 PMID: 7781736

29. Böttiger M, Mellin P, Romanus V, Söderström H, Wesslen T, von Zeipel G. Epidemiological events surrounding a paralytic case of poliomyelitis in Sweden.Bull World Health Organ. 1979;57(1):99-103.PMID: 218746

30. Gefenaite G, Smit M, Nijman HW, Tami A, Drijfhout IH, Pascal A, et al. Comparatively low attendance during Human Papillomavirus catch-up vaccination among teenage girls in the Netherlands: Insights from a behavioral survey among parents. BMC Public Health. 2012;12(1):498. DOI: 10.1186/14712458-12-498 PMID: 22748022

31. World Health Organization (WHO). Summary WHO SAGE conclusions and recommendations on Vaccine Hesitancy. Geneva: WHO; 2015. [Accessed 12 Oct 2015]. Available from: http://www.who.int/immunization/programmes_systems/ summary_of_sage_vaccinehesitancy_2pager.pdf?ua $=1$

32. World Health Organization (WHO). The Guide to Tailoring Immunization Programmes (TIP), Increasing coverage of infant and child vaccination in the WHO European Region. Geneva: WHO; 2013. [Accessed 12 Oct 2015]. Available from: http:// www.euro.who.int/_data/assets/pdf_file/0003/187347/TheGuide-to-Tailoring-Immunization-Programmes-TIP.pdf?ua=1

33. European Centre for Disease Prevention and Control (ECDC). Let's talk about protection - Enhancing childhood vaccination uptake. Stockholm: ECDC; 2012 [Accessed 12 Oct 2015]. Available from: http://ecdc.europa.eu/en/healthtopics/ immunisation/comms-aid/Documents/Vaccine-commsaction-2013.pdf

34. Heymann D, Ahmed Q. The polio eradication end game: what it means for Europe.Euro Surveill. 2014;19(7):20702. DOI: 10.2807/1560-7917.ES2014.19.7.20702 PMID: 24576468

35. The Vaccine Confidence Project. The State of Vaccination Confidence 2015. 2015 [Accessed 12 Oct 2015]. Available from: http://www.vaccineconfidence.org/The-State-of-VaccineConfidence-2015.pdf

36. Yakovenko ML, Gmyl AP, Ivanova OE, Eremeeva TP, Ivanov AP, Prostova MA, et al. The 2010 outbreak of poliomyelitis in Tajikistan: epidemiology and lessons learnt. Euro Surveill. 2014;19(7):20706. DOI: 10.2807/1560-7917.ES2014.19.7.20706 PMID: 24576474

37. Luo HM, Zhang Y, Wang XQ, Yu WZ, Wen N, Yan DM, et al. Identification and control of a poliomyelitis outbreak in Xinjiang, China. N Engl J Med. 2013;369(21):1981-90. DOI: 10.1056/NEJMoa1303368 PMID: 24256377

38. Global Polio Eradication Initiative. Guideline - Responding to a polio outbreak [internet]. 2011. [Accessed 12 Oct 2015]. Available from: http://www.polioeradication.org/ Portals/o/Document/Resources/PolioEradicators/1a. PolioOutbreakGuideline20110107.pdf.

39. World Health Organization (WHO). Report of the 28th Meeting of the European Regional Certification Commission for Poliomyelitis Eradication Copenhagen, Denmark 3-5 June 2014. Generva: WHO; 2014 [Accessed 12 Oct 2015]. Available from: http://www.euro.who.int/ data/assets/ pdf file/0008/256949/Report-of-the-28th-Meeting-of-theEuropean-Regional-Certification-Commission-for-PoliomyelitisEradication.pdf?ua=1

40. Byström E, Lindstrand A, Likhite N, Butler R, Emmelin M. Parental attitudes and decision-making regarding MMR vaccination in an anthroposophic community in Sweden--a qualitative study.Vaccine. 2014;32(50):6752-7. DOI: 10.1016/j. vaccine.2014.10.011 PMID: 25454859

41. Global Eradication Initiative. Responding to a poliovirus outbreak. 2015 [Accessed 12 Oct 2015]. Available from: http:// www.polioeradication.org/Portals/o/Document/Resources/ PolioEradicators/1a.PolioOutbreakGuideline20150220.pdf

42. Luthardt T, Helwig H, Neumann-Haefelin D, Steinitz H, Weineck $B$, Staudt F, et al. [Poliomyelitis epidemic in a district of Freiburg i. Br. in autumn 1975 (author's transl)]. Dtsch Med Wochenschr. 1976;101(37):1345-8. DOI: 10.1055/s-00281104269 PMID: 954590

43. Frantzidou-Adamopoulou F. Poliomyelitis cases in northern Greece during 1976-1990. Eur J Epidemiol. 1992;8(1):112-3. PMID: 1315292

44. Strebel PM, Aubert-Combiescu A, Ion-Nedelcu N, BiberiMoroeanu S, Combiescu M, Sutter RW, et al. Paralytic poliomyelitis in Romania, 1984-1992. Evidence for a high risk of vaccine-associated disease and reintroduction of wild-virus infection. Am J Epidemiol. 1994;140(12):1111-24.PMID: 7998593
45. Krech U. Echovirusinfektionen in der Schweiz während der vergangenen 12 Jahre.Schweiz Med Wochenschr. 1967;97(26):838-41.PMID: 4301858

46. Centers for Disease Control and Prevention (CDC). Poliomyelitis-Finland. Atlanta: CDC; 1985 [Accessed 12 Oct 2015]. Available from: http://www.cdc.gov/mmwr/preview/ mmwrhtml/00000462.htm

47. Kinnunen E, Hovi T, Stenvik M. Outbreak of poliomyelitis in Finland in 1984. Description of nine cases with persisting paralysis.Scand J Infect Dis. 1986;18(1):15-8. DOI: 10.3109/00365548609032300 PMID: 3008307

48. Conyn-van Spaendonck MA, Oostvogel PM, van Loon AM, van Wijngaarden JK, Kromhout D. Circulation of poliovirus during the poliomyelitis outbreak in The Netherlands in 1992-1993. Am J Epidemiol. 1996;143(9):929-35. DOI: 10.1093/oxfordjournals. aje.aoo8836 PMID: 8610706

49. Mulders MN, van Loon AM, van der Avoort HG, Reimerink JH, Ras A, Bestebroer TM, et al. Molecular characterization of a wild poliovirus type 3 epidemic in The Netherlands (1992 and 1993). J Clin Microbiol. 1995;33(12):3252-6.PMID: 8586711

50. Ciofi Degli Atti M, Prevots R, Sallabanda A, Malfait P, Diamantil E, Aylward B, et al. Polio outbreak in Albania, 1996. Euro Surveill. 1997;2(5):37-9.PMID: 12631815

51. World Health Organization (WHO). Poliomyelitis outbreak. Geneva: WHO; 1996 [Accessed 12 Oct 2015]. Available from: http://www.who.int/docstore/wer/pdf/1996/wer7139.pdf

52. Kojouharova M, Zuber PL, Gyurova S, Fiore L, Buttinelli G, Kunchev A, et al. Importation and circulation of poliovirus in Bulgaria in 2001. Bull World Health Organ. 2003;81(7):476-81. PMID: 12973639

53. Korsun N, Kojouharova M, Vladimirova N, Fiore L, Litvinenko I, Buttinelli G, et al. Three cases of paralytic poliomyelitis associated with type 3 vaccine poliovirus strains in Bulgaria. J Med Virol. 2009;81(9):1661-7. DOI: 10.1002/jmv.21545 PMID: 19626606

54. Imported wild poliovirus causing poliomyelitis, Bulgaria, 2001 Wkly Epidemiol Rec. 2001;76(43):332-5. Available from: http:// www.who.int/docstore/wer/pdf/2001/wer7643.pdfPMID: 11702422

\section{License and copyright}

This is an open-access article distributed under the terms of the Creative Commons Attribution (CC BY 4.0) Licence. You may share and adapt the material, but must give appropriate credit to the source, provide a link to the licence, and indicate if changes were made.

This article is copyright of the European Centre for Disease Prevention and Control, 2016. 